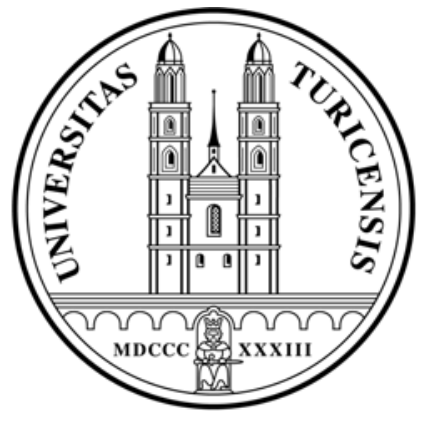

Institute for Empirical Research in Economics

University of Zurich

Working Paper Series

ISSN 1424-0459

Working Paper No. 463

From Rags to Rifles: Deprivation, Conflict and the Welfare State

Dominic Rohner

January 2010 


\title{
From Rags to Rifles: Deprivation, Conflict and the Welfare State
}

\author{
Dominic Rohner \\ University of Zurich
}

October 1, 2009

\begin{abstract}
Historical evidence suggests that poor population groups are more likely to engage in conflict. We construct a theoretical model of the choice between appropriation and production. Fully specified production functions allow for both symmetrical outcomes and for introducing inequalities in abilities and endowments. It is examined under what conditions income and capital redistribution, as well as education, health and poverty-alleviation spending reduce the incentives for appropriation. Empirical evidence is presented that is consistent with the theory.
\end{abstract}

JEL Classification: D02, D74, H50, I30.

Keywords: Conflict, deprivation, welfare state, poverty, appropriative activities.

\section{Introduction}

It is an established empirical finding that deprivation breads conflict ${ }^{1}$. For example, in countries such as South Africa, Rwanda, Guatemala, Nicaragua,

\footnotetext{
${ }^{0}$ Address: Department of Economics, University of Zurich, drohner@iew.uzh.ch.

Acknowledgements: I would like to thank Toke Aidt, Partha Dasgupta, Robert Evans, Francisco Gonzalez and Kalle Moene for especially thoughtful comments. As well, I am grateful for helpful discussions with and comments from Mariya Aleksynska, Steffan Ball, Steven Brams, Paul Collier, Bruno S. Frey, Erik Gartzke, Benedikt Goderis, Anke Hoeffler, Pramila Krishnan, Hamish Low, Andreas Müller, David Myatt, Damjan Pfajfar, Alexander Plekhanov, Emiliano Santoro, Carlos Seiglie, Kevin Sheedy, Nicolas Van de Sijpe, Christopher Wallace, Diego Winkelried, Jun Xue, Fabrizio Zilibotti, seminar participants in Cambridge, Oxford, SOAS (University of London), ETH Zurich and participants of the "Jan Tinbergen Peace Science Conference" in Amsterdam, the "Workshop on Game Theory" in Bolzano, the CSAE conference in Oxford, the Royal Economic Society conference in Nottingham, the conference on "Institutions, Public Policy and Economic Outcomes" in Cambridge, the Grow-Net workshop in Zurich, the PRIO conference in Oslo and the EEA conference in Milano are gratefully acknowledged. Financial support from the Swiss National Science Foundation (SNF Grant "Appropriate Institutions in the Development Process", no. 100014-122636) is gratefully acknowledged.

${ }^{1}$ See for example Fearon and Laitin (2003), Collier and Hoeffler (2004).
} 
El Salvador or Iran poverty and inequality played a major role in the occurrence of political violence during the last century (cf. Muller and Seligson, 1987, for a discussion). A natural question to ask is if the harmful effects of deprivation can be reversed by welfare state policies.

In the present contribution a game-theoretic model of civil war will be built. The model is designed to study how deprivation and redistributive policies affect the level of conflict in the absence of property rights protection. First, it will be shown how poverty fuels war by lowering the opportunity cost of appropriative activities. ${ }^{2}$ In the main part of the theoretical analysis it will be assessed under what conditions welfare state institutions can lower the risk of appropriative conflict. In particular, the effects of income transfers, capital redistribution and productivity-enhancing policies such as education and public health programmes will be studied. Towards the end of the paper, some empirical evidence will be presented that is consistent with the model's predictions.

Various literatures are relevant for the present contribution. Macro- and micro-level empirical evidence suggests that it makes sense to link the issues of conflict, deprivation, inequality and welfare state institutions: Poverty (Fearon and Laitin, 2003; Collier and Hoeffler, 2004; Do and Iyer, 2007; Collier and Rohner, 2008), inequality (Muller and Seligson, 1987; Deininger, 2003), and lack of education (Deininger, 2003) have been found to increase the risk of political violence. Justino (2005) has found that redistributive policies have been effective in reducing unrest on the local level in India.

Despite the empirical results, only relatively few theoretical models have focused on these issues. The contributions of Grossman (1995), Azam (2001) and Noh (2002) examine the deterrent effect of income transfers on appropriative activities. Brito and Intriligator (1985) link the possibility of avoiding inter-state wars through resource transfers with the issue of imperfect information, and Grossman (1994) emphasizes that land reforms can result in less appropriative activities. A related paper of Dal Bo and Dal Bo (2008) studies the effect of redistribution between capital- and labour-intensive industries.

However, most of these important contributions studying particular welfare state policies use models in which asymmetry between the two types of players is inherent in the model. As the roles, for example, predator versus prey, or landowner versus peasant families, are assigned from the beginning, these models do not account for a symmetric outcome, with all players choosing some part of appropriative activities. ${ }^{3}$ Moreover, these models focus on

\footnotetext{
${ }^{2}$ As defined in the present contribution, appropriative activities include actions taken with the aim of altering the existing distribution of social wealth in favour of the player who takes the action. The focus lies on appropriation related to civil wars.

${ }^{3}$ Of course there are some other papers in the economics of conflict literature that allow for symmetrical outcomes with all players choosing some part of time for appropriation (e.g. Grossman and Kim, 1995). However, they do not treat the impact of welfare state
} 
one policy issue at a time and do not allow for considering the impact of various welfare state institutions within one single framework. Furthermore, these articles focus mainly on income transfers, but do not treat other welfare state policies such as capital redistribution ${ }^{4}$, education ${ }^{5}$, health policy and anti-poverty-programmes.

Thus, there is still an important need for further research linking conflict and the welfare state. The contribution of the present paper is of three kinds: First, I will build a conflict model that allows for symmetrical outcomes and includes fully specified production functions, enabling us to study the impact of several distinct welfare state policies at the same time. Second, I will not only focus on income taxation, but will as well analyze capital redistribution, education spending, health policy and anti-poverty-programmes, which have rarely been treated in the context of our research question. Third, the impact of welfare state policies will be assessed empirically with the help of panel data for 155 countries over a period of 40 years. The empirical results are in line with the model's predictions, although due to a lack of more detailed data it is not possible to rule out all possible alternative mechanisms.

The remaining part of the present contribution is organized as follows: Section 2 builds a simple model of appropriative conflict, and section 3 focuses on the impact of several welfare state policies. Section 4 presents some empirical evidence and section 5 concludes.

\section{The Model}

\subsection{The Assumptions}

Since for armed conflicts usually large groups of the population of a given country or region are involved, a framework with two aggregate players is appropriate. Each player represents the aggregate choice of individuals being part of two larger groups of the society. For example, one player could represent the people from some ethnic group A, and the other player people from another ethnic group B.

Both groups have the choice between productive (L) and appropriative (F) activities. As defined earlier, appropriative activities are unproductive and aim to alter the existing distribution of social welfare. Even though they may be utility maximizing for a particular group, they are socially harmful and constitute a net deadweight loss on the level of the society as a whole.

${ }^{4}$ The model studying land reforms in Grossman (1994) is quite specifically designed for treating the factor of production "land". It cannot easily be generalized for other kinds of endowments, such as capital. Similarly, Brito and Intriligator's (1985) model focuses on the question of imperfect information, and is not designed for analyzing the impact of welfare state policies, such as capital redistribution.

${ }^{5}$ Grossman and Kim (2003) link the issues of education and conflict. However, they focus on explaining differences across countries in educational policies.
} 
There is only one output good, $\mathrm{y}$, which is produced using two inputs, labour (L) and capital (K). Whereas $\mathrm{L}$ is the choice variable, $\mathrm{K}$ is assumed to be a given endowment of capital and land.

The payoff of each group consists of the non-stolen part of its own production plus the part of the opponent's production that it steals. For simplicity, the appropriated part of the other group's production depends linearly on the time share a group spends on appropriative activities. I include a parameter $\rho$ for group 1 (and $\theta$ for group 2) which represents a friction in the appropriation activity. Our friction loss is similar to the one of iceberg trade costs. A part of the stolen production from the other group is lost due to fighting or transportation.

We have the following payoff (utility) functions for the two groups:

$$
V_{i}=\left(1-F_{j}\right) y_{i}+F_{i} y_{j}^{\rho}=L_{j} y_{i}+\left(1-L_{i}\right) y_{j}^{\rho}
$$

subject to the time constraint $L_{i}+F_{i}=1$.

Moreover, we include Cobb-Douglas production functions $y_{1}=\alpha L_{1}^{a} K_{1}^{b}$ and $y_{2}=\beta L_{2}^{c} K_{2}^{d}$, where $\alpha, \beta=$ total factor productivities; a,b,c,d=parameters. The functions show decreasing marginal returns for the choice variable $\mathrm{L}$ and for $\mathrm{K}$, i.e. $\mathrm{a}<1, \mathrm{~b}<1, \mathrm{c}<1, \mathrm{~d}<1$. There is no need to make any restrictions with respect to the level of returns to scale (although one would typically think of constant returns to scale). We get the following payoff function for group 1 (this is analogous for group 2):

$$
V_{1}=L_{2} \alpha L_{1}^{a} K_{1}^{b}+\left(1-L_{1}\right) \beta^{\rho} L_{2}^{c \rho} K_{2}^{d \rho}
$$

Given that the main purpose of the paper is to study the effects of redistribution on the time devoted to production and appropriation, it is desirable to include production functions with decreasing returns to labour and complementarities between labour and capital (as is the case of the Cobb-Douglas form). Like in several recent papers we include linear appropriation technologies (e.g. Rohner, 2006; Besley and Persson, 2009, 2009b), and model contest as mutual stealing. This has the crucial advantage that we can incorporate production functions with decreasing returns to labour, while keeping the model analytically solvable. Indeed, for the main alternative difference- or ratio-form contest success functions with Cobb-Douglas production functions in the first order conditions the choice variable $L_{1}$ would take various powers ${ }^{6}$, ruling out an analytical solution. Thus, in these

\footnotetext{
${ }^{6}$ This is for example the case for the difference-form specification, $V_{1}=\left(\frac{1}{2}+\psi((1-\right.$ $\left.\left.\left.L_{1}\right)-\left(1-L_{2}\right)\right)\right)\left(\alpha L_{1}^{a} K_{1}^{b}+\beta^{\rho} L_{2}^{c \rho} K_{2}^{d \rho}\right)$, or the following ratio-form specification, $V_{1}=$ $\frac{\left(1-L_{1}\right)}{\left(1-L_{1}\right)+\left(1-L_{2}\right)}\left(\alpha L_{1}^{a} K_{1}^{b}+\beta^{\rho} L_{2}^{c \rho} K_{2}^{d \rho}\right)$.
} 
cases the model would only be analytically solvable with simplified production functions featuring constant returns to labour (and implying increasing returns to scale when capital is included).

The advantages of our modelling framework come at the price of slightly more complicated comparative statics. As the model features multiple equilibria we will have to focus on how welfare state policies can rotate the reaction functions in a way that makes the "low appropriation" equilibrium feasible and increases its basin of attraction, and we cannot simply perform directly comparative statics with a unique stable interior equilibrium. However, as discussed in Appendix A the predictions of the model do not critically depend on the functional forms chosen and are robust to a wide range of modelling approaches. In particular, for frameworks with standard difference- or ratio-form contest success functions yielding unique interior Nash equilibria the predicted impact of various welfare state policies would be extremely similar.

\subsection{The Equilibria}

Setting $\frac{\partial V_{i}}{\partial L_{i}}$ equal to zero, we get the first order conditions (the second order conditions hold). Reformulating, the following expression is obtained for group 1 (it is analogous for group 2):

$$
L_{1}=\left(\frac{\alpha a}{\beta^{\rho}}\right)^{\frac{1}{1-a}} K_{1}^{\frac{b}{1-a}} K_{2}^{\frac{-d \rho}{1-a}} L_{2}^{\frac{1-c \rho}{1-a}}
$$

Given the time constraint, the labour time is bounded between 0 and 1 , i.e. $0 \leq L_{i} \leq 1$.

For describing graphically the Nash equilibria we can, without loss of generality, first focus on a symmetrical case where $a=c, b=d, \alpha=\beta, \rho=\theta$. Figure $1^{7}$ displays the reaction functions for particular values of the different parameters. We will first consider the case of a fighting-trap. For $\left(\alpha^{1-\rho} a\right)^{\frac{1}{1-a}} K_{i}^{\frac{b}{1-a}} K_{j}^{-\frac{d \rho}{1-a}}<1$ (as in the case of the dotted curves RF1 and RF2), there is only one single Nash equilibrium, $(0,0)$. If group 1's (black) reaction function rotates towards the north-west, and group 2's (grey) reaction function rotates towards the south-east, we will eventually end up in the case where $\left(\alpha^{1-\rho} a\right)^{\frac{1}{1-a}} K_{i}^{\frac{b}{1-a}} K_{j}^{-\frac{d \rho}{1-a}}=1$, with the two Nash equilibria $(0,0)$ and $(1,1)$. This corresponds to the solid lines RF1' and RF2'. The outcome $(1,1)$ is Pareto-superior to $(0,0)$. Continuing to rotate the reaction functions further (not displayed in figure 1) will lead to the case

\footnotetext{
${ }^{7}$ Case $1: \mathrm{a}=0.5, \mathrm{~b}=0.5, \rho=0.5, \alpha=2, K_{1}=1, K_{2}=1$. The black dotted line is the reaction function of group 1 (RF1), whereas the grey dotted line refers to the reaction function of group 2 (RF2). Case 2: $\mathrm{a}=0.5, \mathrm{~b}=0.5, \rho=0.5, \alpha=4, K_{1}=1, K_{2}=1$. The black solid line represents the reaction function of group 1 (RF1'), the grey solid line corresponds to the reaction function of group 2 (RF2').
} 


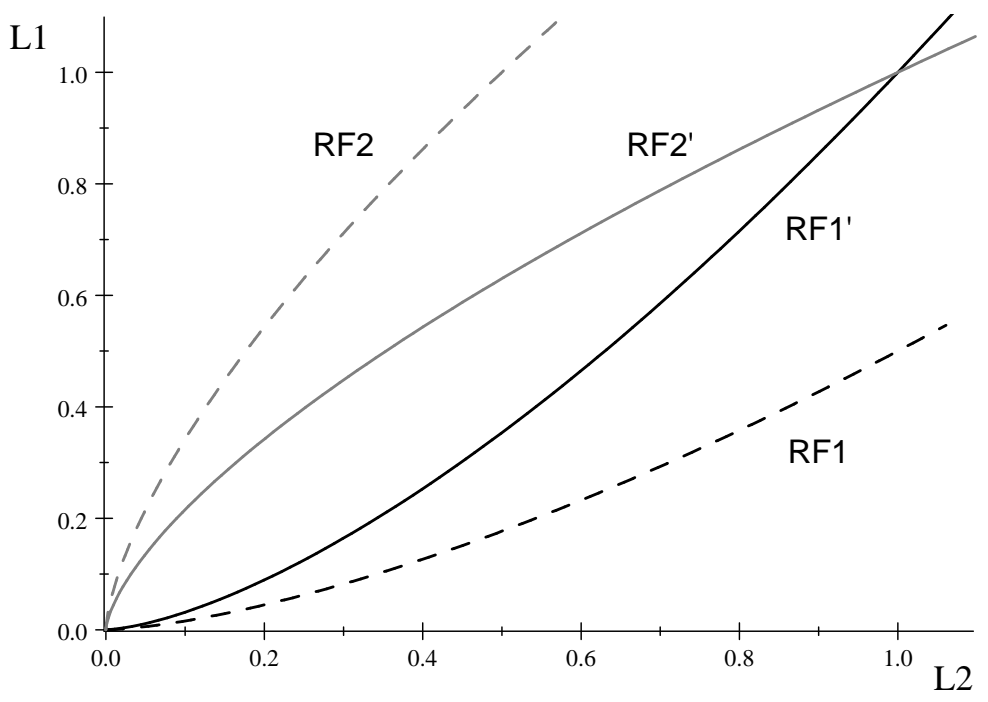

Figure 1: Reaction functions for different parameter values

where $\left(\alpha^{1-\rho} a\right)^{\frac{1}{1-a}} K_{i}^{\frac{b}{1-a}} K_{j}^{-\frac{d \rho}{1-a}}>1$. In this situation we obtain three Nash equilibria, $(0,0),(1,1)$, and an intermediate one. If we assume simple out-ofequilibrium dynamics ${ }^{8}$, we are able to describe the basins of attraction for the case with three equilibria (cf. figure 2).

The two extreme value equilibria E', $(0,0)$, and E", $(1,1)$, in figure 2 are stable, whereas the intermediate equilibrium E" 'is unstable. Towards the south-west of the intermediate equilibrium is the basin of attraction of the "bad" equilibrium E', $(0,0)$, and in the north-east of the intermediate equilibrium is the basin of attraction of the "good" equilibrium E", $(1,1)$. The more RF1 rotates to the north-west and the more RF2 rotates to the south-east, the more the intermediate equilibrium E" moves to the south-west. This results in the basin of attraction of the "bad" equilibrium becoming smaller and the basin of attraction of the "good" equilibrium becoming larger. ${ }^{9}$

\footnotetext{
${ }^{8}$ For fully characterizing the out-of-equilibrium dynamics, a dynamic framework with differential equations is needed. Deriving a dynamic version of our static model is straightforward. Assuming that the labour time of group 1 increases linearly in the difference between the marginal returns to productive activities and to appropriative activities, we obtain: $\dot{L_{1}}=\zeta\left(L_{2} \alpha a L_{1}^{a-1} K_{1}^{b}-\beta^{\rho} L_{2}^{c \rho} K_{2}^{d \rho}\right)$, where $\zeta=$ parameter related to the speed of adjustment. It is analogous for $\dot{L_{2}}$. Putting $\dot{L}_{1}=\dot{L}_{2}=0$, we obtain the equilibrium lines that are identical to the reaction functions of the static model. The equilibria correspond to the intersection of the equilibrium lines. A similar modelling approach for making a static model dynamic is used and discussed in more detail in Rohner and Frey (2007).

${ }^{9}$ For our kind of setting with strategic complementarities, the issue of equilibrium selection can easily be treated in a more explicit way using global games. In Rohner and Frey (2007) it is shown that, for a similar model structure, the results from comparative
} 


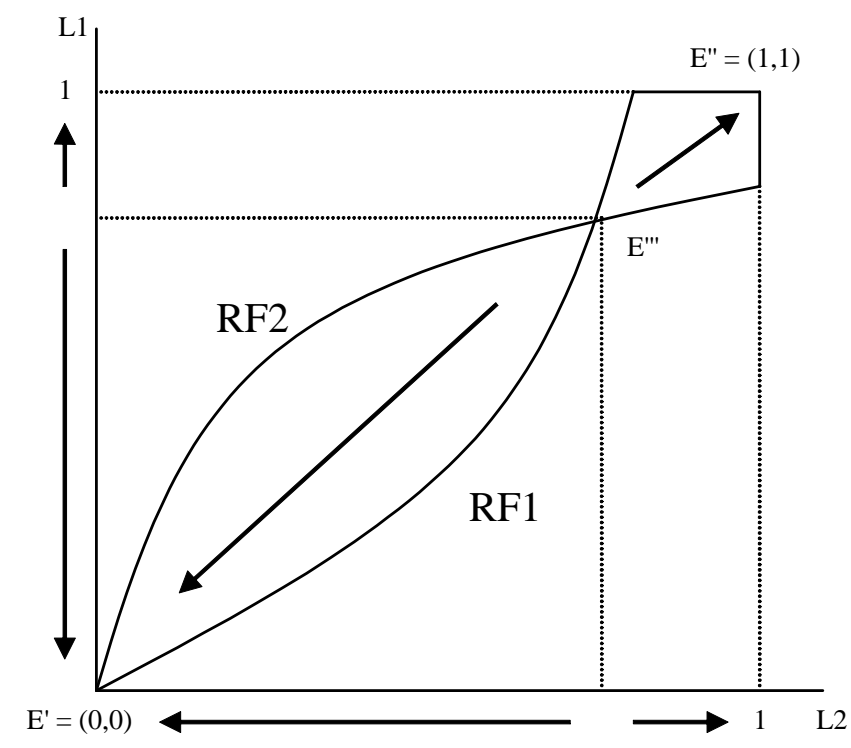

Figure 2: Basins of attraction for the case of three equilibria

The focus of the comparative statics lies on how to achieve the "good" outcome $(1,1)$, if the country is initially stuck in the "fighting-trap" $(0,0) .{ }^{10}$ Therefore, it is assumed that at first $\left(\alpha^{1-\rho} a\right)^{\frac{1}{1-a}} K_{i}^{\frac{b}{1-a}} K_{j}^{-\frac{d \rho}{1-a}}<1$. It will be shown that under certain conditions welfare state policies rotate group 1's reaction function towards the north-west, and group 2's reaction function towards the south-east in figure 1. If the policy shock is big enough, it becomes possible to achieve multiple equilibria, whereas $(0,0)$ is still possible, but $(1,1)$ is now a potential outcome as well. Thus, the framework becomes a "coordination"-game. Further, as seen before, the more RF1 rotates to the north-west and RF2 rotates to the south-east, the smaller becomes the basin of attraction of the "bad" equilibrium and the larger becomes the basin of attraction of the "good" equilibrium. In this case the likelihood of ending up in a "fighting-trap" decreases, and the good outcome $(1,1)$ is more likely to be achieved.

As explained above, rotations of RF1 to the north-west and of RF2 to the south-east are always a good thing in terms of political stability. Therefore, in such a setting of multiple equilibria it is most convenient for

statics are identical for an explicit equilibrium selection model using global games and for an approach based on shifts in the reaction functions and basins of attractions, as is done in the present contribution.

${ }^{10}$ The present analysis is based on the framework of a static game. If the game were to be repeated, cooperation could be fostered through strategies such as "grim strategy" or "tit-for-tat". 
the comparative statics section to focus on the rotations. ${ }^{11}$

For the sake of completeness, we can compute the value of the intermediate Nash equilibria, by plugging one reaction function into the other. The intermediate equilibrium for $L_{1}$ is given by equation (4) (this is analogous for group 2).

$$
L_{1}=\left[\left(\frac{\alpha a}{\beta^{\rho}}\right)^{\frac{1}{1-a}}\left(\frac{\beta c}{\alpha^{\theta}}\right)^{\frac{1-c \rho}{(1-a)(1-c)}} K_{1}^{\left(\frac{b}{1-a}-\frac{b \theta(1-c \rho)}{(1-a)(1-c)}\right)} K_{2}^{\frac{d(1-\rho)}{(1-a)(1-c)}}\right]^{\frac{1}{1-\frac{(1-a \theta)(1-c \rho)}{(1-a)(1-c)}}}
$$

\subsection{The Role of Poverty and Development}

In the present subsection we shall discuss how in an initial framework without state intervention the level of productivity and capital endowments matter for conflict.

Proposition 1 i) When a group 1 has a higher productivity $\alpha$ and greater capital endowment $K_{1}$, ceteris paribus it is less likely to spend time for appropriative activities. ii) A general increase in development (i.e. a parallel increase in $\alpha$ and $\beta$ ), makes appropriative conflict less likely.

Proof. i) Follows from the derivatives $\partial L_{1} / \partial \alpha>0$ and $\partial L_{1} / \partial K_{1}>0$ of equation (3). A larger $L_{1}$ (for a given $L_{2}$ ) corresponds to an upward rotation of group 1's reaction function, which decreases the basin of attraction of the equilibrium $(0,0)$. ii) This is due to $\rho<1$.

Intuitively, the higher the total factor productivity and the bigger the capital endowment of a group, the greater the opportunity cost of engaging in appropriation.

The prediction of the model that higher total factor productivity results in lowered incentives for engaging in civil conflict is in line with the macrolevel evidence of Fearon and Laitin (2003), Collier and Hoeffler (2004), Collier and Rohner (2008) and Collier, Hoeffler and Rohner (2009), and microlevel evidence of Do and Iyer (2007). ${ }^{12}$

\footnotetext{
${ }^{11}$ Appendix $\mathrm{A}$ is devoted to the discussion of alternative frameworks with simplified production functions but featuring unique interior equilibria, thus allowing simpler (in equilibrium) comparative statics. However, all predictions on the impact of welfare state policies are very similar for all these alternative frameworks.

${ }^{12}$ These empirical findings are challenged by Krueger and Maleckova (2003) and Berrebi (2007), who find no or even a positive correlation between education and the likelihood of engaging in terrorism. However, their findings could be due to an excess supply of volunteers and the terrorist organization picking the most skilled ones. In this case, raising the general education level would not lead to more terrorism and conflict. Another explanation for their results is that schooling in countries like Palestine is not always productivityenhancing, but often contains a strong element of indoctrination, hate campaigns and misinformation (Berrebi, 2003; Gentzkow and Shapiro, 2004).
} 


\section{The Effects of Welfare State Policies}

In this part we will focus on the impact of different welfare state policies on the groups' decisions between productive and appropriative activities. We should note that the first-best policy would be the enforcement of property rights, eliminating appropriative activities altogether. Accordingly, welfare state institutions represent only a second-best policy that becomes important when property rights protection is imperfect.

The analysis of the present section builds on the assumption that the state in question can raise taxes and assure redistribution, but is not able to fully secure property rights. For many developing countries such an assumption is reasonable, as states can be "strong" with respect to one policy dimension, but "weak" with respect to the other dimension.

In countries such as Sri Lanka, Colombia, Brazil or Nigeria raising taxes and conducting fiscal and welfare state policies is possible. The presence of rebel groups in some of those countries makes the collection of taxes more difficult in some regions than in others, but larger firms cannot escape taxation independently of their location. Also, some kinds of taxes, such as export taxes or import tariffs (which de facto at least partially reduce the surplus of the domestic firms) can be levied quite independently of the ongoing conflict.

At the same time the effective protection of property rights is not assured, at least in large parts of those countries. In many areas the slender police and army forces do not even dare to enter, and in others an effective protection of property rights is made impossible by the poor law system. Even in parts of some OECD-countries property rights are not effectively protected (e.g. Chiapas in Mexico or some parts of Southern Italy), although taxation is possible.

We can regard the society as being composed of two types of groups: One "high productivity" and one "low productivity". Our framework is flexible enough to apply to class conflicts or to conflicts between a dominant ethnic group and a disenfranchised ethnic minority group.

In the framework of our model, the "low productivity" group would typically have greater incentives than the "high productivity" one for choosing appropriative activities (cf. proposition 1) The goal of the following analysis is to assess under what conditions welfare state policies could prevent the two groups, and in particular the "low productivity" group, from appropriative activities.

\subsection{Income Taxation for Transfers}

First, we will focus on transfers from the high income group to the low income group by the means of proportional income taxation at a rate $t$. The tax revenue is used for the provision of (non-appropriable) public goods 
and services that benefit both groups to an equal extent. For simplicity, it is assumed that each group receives public goods and services of the amount $\frac{t\left(y_{1}+y_{2}\right)}{2} .{ }^{13}$ Given that each group contributes different amounts of tax payments but receives the same level of public goods and services in return, this setting corresponds to net transfers from the high income group to the low income group.

The timing is as follows. First, groups decide how much labour time they want to invest in production. Then, the state taxes a proportion $t$ of the total production income of both groups. Finally, the groups appropriate a part of the disposable output of the opponent (where $F_{i}=1-L_{i}$ ) and the state provides its goods and services. The payoff function of group 1 becomes (it is analogous for group 2):

$$
V_{1}=L_{2}(1-t) y_{1}+\left(1-L_{1}\right)\left[(1-t) y_{2}\right]^{\rho}+\frac{t\left(y_{1}+y_{2}\right)}{2}
$$

Introducing the production function in (5), we obtain:

$$
V_{1}=L_{2}(1-t) \alpha L_{1}^{a} K_{1}^{b}+\left(1-L_{1}\right)(1-t)^{\rho} \beta^{\rho} L_{2}^{c \rho} K_{2}^{d \rho}+\frac{t\left(\alpha L_{1}^{a} K_{1}^{b}+\beta L_{2}^{c} K_{2}^{d}\right)}{2}
$$

From the first order conditions follows reaction function (7) for group 1 (for group 2 the result is similar):

$$
L_{1}=\left[\frac{\alpha a K_{1}^{b}}{\beta^{\rho} L_{2}^{c \rho} K_{2}^{d \rho}}\right]^{\frac{1}{1-a}}\left[\frac{(1-t) L_{2}+\frac{t}{2}}{(1-t)^{\rho}}\right]^{\frac{1}{1-a}}
$$

Taking the first derivative of (7) with respect to t, we can see under what conditions more income taxation leads to more or less appropriative activities. As we are interested in the direction of the shift of the reaction function, we have to focus on the change in $L_{1}$ for a change in $t$, holding $L_{2}$ constant at a given level. The approach will be similar in the other subsections.

$$
\begin{aligned}
\frac{\partial L_{1}}{\partial t}= & \left(\frac{1}{1-a}\right)\left[\frac{\alpha a K_{1}^{b}}{\beta^{\rho} L_{2}^{c \rho} K_{2}^{d \rho}}\right]^{\frac{1}{1-a}}\left[\frac{(1-t) L_{2}+\frac{t}{2}}{(1-t)^{\rho}}\right]^{\frac{a}{1-a}} \\
& {\left[\frac{\frac{1}{2}-(1-\rho) L_{2}+\frac{t \rho}{2(1-t)}}{(1-t)^{\rho}}\right] }
\end{aligned}
$$

Whether the expression (8) is positive or negative depends exclusively on the numerator of the last term in (8) (as all other terms are unambiguously positive).

\footnotetext{
${ }^{13}$ The results are robust to alternative ways of modelling public goods and service provision.
} 


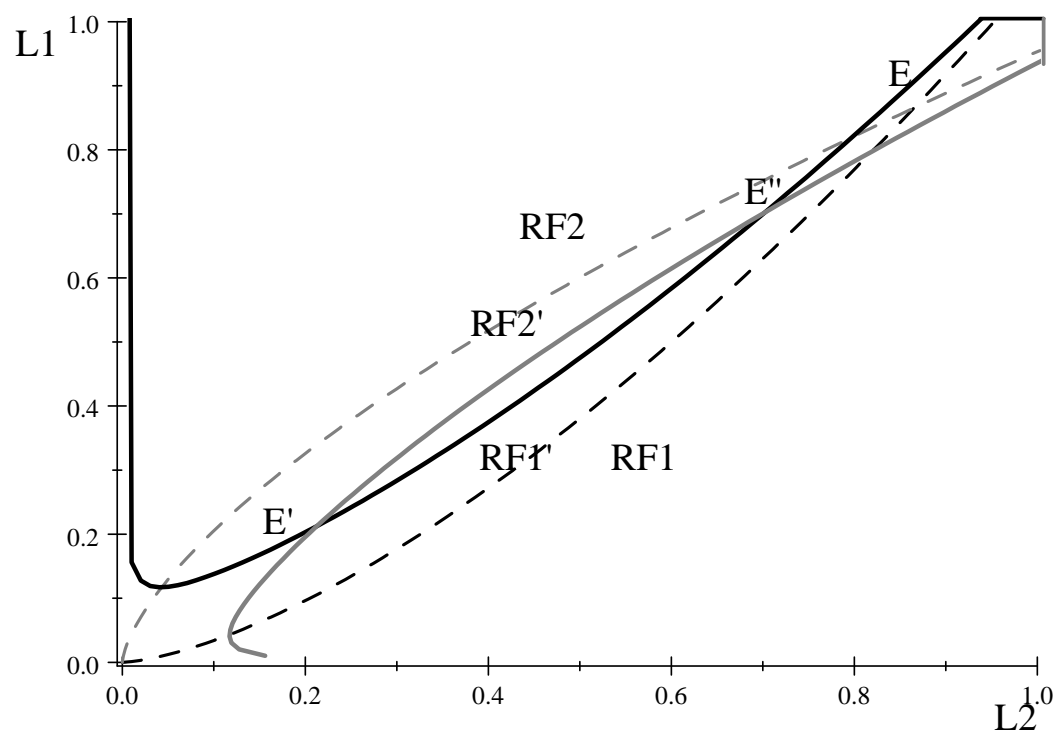

Figure 3: The impact of income taxation for an intermediate level of appropriation friction

Note that the "high appropriation" equilibrium, which was $L_{1}=L_{2}=0$ for zero taxation, $t=0$, becomes now interior for positive taxation levels. This new interior equilibrium is stable. Mathematically, we can easily see that $\frac{1}{2}-(1-\rho) L_{2}+\frac{t \rho}{2(1-t)}>0$ always holds for $L_{2}=0$. Thus, independently of the parameter values, the "high appropriation" equilibrium with income taxation is always characterized by positive levels of labour, i. e. $L_{1}>0$, $L_{2}>0$.

This new interior "high appropriation" equilibrium is displayed as E' for particular parameter values ${ }^{14}$ in figure 3 . The dashed curves correspond to the case of no income taxation, $\mathrm{t}=0$, while the solid curves represent a case of a proportional income tax of twenty percent, $\mathrm{t}=0.2$.

The effect of income taxation on the position of the unstable equilibrium (labelled E"' in figure 2, and labelled E, resp. E" in the present figure 3) is a priori ambiguous and depends on the parameter values. For low and intermediate levels of appropriation friction (i.e. $\rho \geq 0.5), \frac{1}{2}-(1-\rho) L_{2}+$ $\frac{t \rho}{2(1-t)}>0$ always holds, and this intermediate unstable equilibrium moves towards the origin, increasing thereby the basin of attraction of the stable "low appropriation" equilibrium with $L_{1}=L_{2}=1$. For this case income taxation always unambiguously decreases the scope for conflict. This is displayed as the move from E to E" in figure 3 (where $\rho=0.5$ ).

\footnotetext{
${ }^{14} \mathrm{As}$ in figure 1 , we set for figure $3 \mathrm{a}=\mathrm{b}=0.5, \rho=0.5, K_{1}=K_{2}=1$. Further, $\alpha=\beta=4.3$. For the dashed curves $\mathrm{t}=0$, while for the solid curves $\mathrm{t}=0.2$.
} 
For more appropriation friction and thus lower levels of $\rho$, this unstable intermediate level can sometimes move towards $(1,1)$, thereby decreasing the basin of attraction of the "good" equilibrium. We obtain the following proposition:

Proposition 2 An income transfer from the better-off to the worse-off group through income taxation always leads to a move of the "high appropriation" equilibrium from $L_{1}=0, L_{2}=0$ to a stable interior equilibrium with $L_{1}>0$, $L_{2}>0$.

The resulting change in the unstable intermediate equilibrium (labelled $E$ in figure 3) is a priori ambiguous and depends on the parameter values. This equilibrium moves towards the origin (and thus increases the basin of attraction of the "good" equilibrium $(1,1))$ if $\frac{1}{2}-(1-\rho) L_{2}+\frac{t \rho}{2(1-t)}>0$, i.e. for a low $L_{2}$, for a high $\rho$ and a high $t$.

Proof. Follows from equation (8) and the discussion above.

These findings can be interpreted as follows. For a high $\rho$, which corresponds to a low friction of stealing, more redistribution decreases the incentives for appropriative activities. Intuitively, if a group knows that it will get a substantial part of the other group's production through redistribution, it will have less incentives to steal. For a very low $\rho$, stealing becomes in any case less of an issue, and the dominant impact of a rise in taxes are the reduced incentives for productive activities.

The situation is similar for the level of $L_{2}$. If we are in a fighting-trap (low level of $L_{2}$ ), the disincentives of stealing dominate, whereas if a country is doing well (high level of $L_{2}$ ), the disincentives of taxation on production effort dominate.

One can think of the redistribution process as institutionalized "stealing" from the rich for giving it to the poor, managed by the state. Unlike redistribution through appropriative activities, redistribution through the state does not involve a friction cost of fighting and does not lead to an opportunity cost of time spent for appropriation. More formally, for a given amount $\mathrm{M}$ transferred from a better-off group 1 to a worse-off group 2, the beneficiary (group 2) prefers redistribution through the welfare state rather than through appropriation, as in the former case group 2 receives the full amount $M$ and has freed time for productive activities, while in the latter case group 2 only receives an amount $\mathrm{M}^{\prime}<\mathrm{M}$ (due to the friction of fighting). Group 1 loses under both mechanisms an amount $M$ and is indifferent. Thus, redistribution through the welfare state of a given amount M is Pareto-superior to appropriation, as at least one group is better off and 
no group is worse off. ${ }^{1516}$

Under what conditions does a government have incentives to implement a redistribution policy? The decision of a generally benevolent government is considered, whose utility function is a weighted combination of the utility functions of groups 1 and 2: $V_{G}=\varphi V_{1}+(1-\varphi) V_{2}$, where $\varphi=$ weight attributed to group 1. If the government is composed of only members of group 1 (resp., group 2), we would have $\varphi=1$ (resp., $\varphi=0$ ).

Would a government that is exclusively composed of members of group 1 ever have incentives for redistributing output or capital if group 1 happens to be the wealthier group? First, the case where $\left(\frac{\alpha a}{\beta^{\rho}}\right)^{\frac{1}{1-a}} K_{1}^{\frac{b}{1-a}} K_{2}^{\frac{-d \rho}{1-a}}<1$ and $\left(\frac{\beta c}{\alpha^{\theta}}\right)^{\frac{1}{1-c}} K_{2}^{\frac{d}{1-c}} K_{1}^{\frac{-b \theta}{1-c}}<1$ should be considered. In this situation, the reaction functions only intersect once at the fighting equilibrium $(0,0)$, which results in both groups and the government all receiving a payoff of zero, i.e. $V_{1}=0, V_{2}=0, V_{G}=0$. Clearly, redistribution would be advantageous for everybody, at least up to the point when the reaction functions intersect a second time and $(1,1)$ becomes feasible, i.e. where $\left(\frac{\alpha a}{\beta^{\rho}}\right)^{\frac{1}{1-a}} K_{1}^{\frac{b}{1-a}} K_{2}^{\frac{-d \rho}{1-a}}=1$ and $\left(\frac{\beta c}{\alpha^{\theta}}\right)^{\frac{1}{1-c}} K_{2}^{\frac{d}{1-c}} K_{1}^{\frac{-b \theta}{1-c}}=1$. Thus, any government would have incentives to implement redistribution. From that point onwards a government that is mainly composed of members of the wealthier group would face a tradeoff, as on the one hand redistribution leads to direct losses of the better-off group, but on the other hand also reduces the risk of conflict. In order to treat this outcome more explicitly, we would have to explicitly address the issue of equilibrium selection, which we do not do due to space limitations.

\subsection{Redistribution of Capital and Land}

It has been shown in the literature that conflicts are often associated with land and asset inequality (André and Platteau, 1998; Deininger, 2003). However, it is controversial if and under what conditions reforms leading to a more egalitarian land distribution can reduce the risk of conflict. While some scholars argue that land reforms can reduce the scope for conflict (Grossman, 1994; Sweig, 2002), other scholars stress that in some cases land redistribution has either no effects or can even increase the risk of conflict due to enhanced competition (Alston, Libecap and Mueller, 2000; Bandiera, 2003).

\footnotetext{
${ }^{15}$ We have not taken the increase in the demand for "leisure" and the administrative costs caused by redistribution (e.g. individuals must comply with means-tested criteria, the need to travel long distances etc) into account. These factors can result in a deadweight loss.

${ }^{16}$ An interesting variation of the policy of forfeit income transfers would be transfers dependent on the receiving group choosing a zero (or very low) level of appropriation. Such conditional transfers could enhance the incentives of behaving in a peaceful way.
} 
In the present subsection we shall assess theoretically under what conditions capital and land redistribution ${ }^{17}$ can reduce the scope for conflict.

Each group's time spent for productive activities increases in its own capital and decreases in the opponent's capital. We can easily see this by taking for equation (3) the first derivative of $L_{1}$ with respect to $K_{1}$ (displayed in equation (9)) and $K_{2}$ (displayed in equation (10)). This is similar for the reaction function of the second group.

$$
\begin{aligned}
& \frac{\partial L_{1}}{\partial K_{1}}=\left(\frac{b}{1-a}\right)\left(\frac{\alpha a}{\beta^{\rho}}\right)^{\frac{1}{1-a}} K_{1}^{\frac{a+b-1}{1-a}} K_{2}^{\frac{-d \rho}{1-a}} L_{2}^{\frac{1-c \rho}{1-a}}>0 \\
& \frac{\partial L_{1}}{\partial K_{2}}=\left(\frac{-d \rho}{1-a}\right)\left(\frac{\alpha a}{\beta^{\rho}}\right)^{\frac{1}{1-a}} K_{1}^{\frac{b}{1-a}} K_{2}^{\frac{a-d \rho-1}{1-a}} L_{2}^{\frac{1-c \rho}{1-a}}<0
\end{aligned}
$$

Thus, the impact of capital redistribution in the present framework is ambiguous $^{18}$. If capital is redistributed from group 1 to group 2 , typically group 2 has smaller incentives for appropriative activities, but group 1's incentives for fighting increase. Simple capital transfers between large population segments do not appear to be an efficient policy for avoiding conflict.

However, there is a caveat to this result, when not all capital is employed in production (due to limitations and constraints of the production technology), but a part of it is consumed. We can assume for now that there is a maximum amount of capital, $K^{*}$, which the production technology allows for.

Assume that initially group 1 has excess capital: $K_{1}=K^{*}+K_{E X}$, where $K_{E X}=$ excess capital not employed in the production. For a policy that redistributes $K_{E X}$ from group 1 to group 2, the employed capital $K_{1}$ remains constant at $K^{*}$, while $K_{2}$ increases by an amount $K_{E X}$. The impact on $L_{1}$ equals $\frac{\partial L_{1}}{\partial K_{2}}=\left(\frac{-d \rho}{1-a}\right)\left(\frac{\alpha a}{\beta^{\rho}}\right)^{\frac{1}{1-a}} K_{1}^{\frac{b}{1-a}} K_{2}^{\frac{a-d \rho-1}{1-a}} L_{2}^{\frac{1-c \rho}{1-a}}<0$. Group 1 produces less, as group 2 becomes a better prey due to an increased capital stock. For group 2, the effect equals $\frac{\partial L_{2}}{\partial K_{2}}=\left(\frac{d}{1-c}\right)\left(\frac{\beta c}{\alpha^{\theta}}\right)^{\frac{1}{1-c}} K_{2}^{\frac{c+d-1}{1-c}} K_{1}^{\frac{-b \theta}{1-c}} L_{1}^{\frac{1-a \theta}{1-c}}>0$. If the parameter values of the two groups are similar, the second effect of

\footnotetext{
${ }^{17}$ The parameter $\mathrm{K}$ in the model captures both physical capital and land. Including an additional factor of production for land would not affect the results.

${ }^{18}$ The impact of capital redistribution can be assessed in a more formal way. If the intermediate equilibrium moves to the south-west (which corresponds to a decrease of $L_{1}$ and $L_{2}$ ), the basin of attraction of the good equilibrium increases and the basin of attraction of the bad equilibrium decreases. This leads to a lower risk of conflict. Formally, this corresponds to the following condition for group $1 . L_{1}^{\prime}=$ $\left[\left(\frac{\alpha a}{\beta^{\rho}}\right)^{\frac{1}{1-a}}\left(\frac{\beta c}{\alpha^{\theta}}\right)^{\frac{1-c \rho}{(1-a)(1-c)}}\left(K_{1}+\Delta t\right)^{\left(\frac{b}{1-a}-\frac{b \theta(1-c \rho)}{(1-a)(1-c)}\right)}\left(K_{2}-\Delta t\right)^{\frac{d(1-\rho)}{(1-a)(1-c)}}\right]^{\frac{1}{1-\frac{(1-a \theta)(1-c \rho)}{(1-a)(1-c)}}}$
$\quad<L_{1}=\left[\left(\frac{\alpha a}{\beta^{\rho}}\right)^{\frac{1}{1-a}}\left(\frac{\beta c}{\alpha^{\theta}}\right)^{\frac{1-c \rho}{(1-a)(1-c)}} K_{1}^{\left(\frac{b}{1-a}-\frac{b \theta(1-c \rho)}{(1-a)(1-c)}\right)} K_{2}^{\frac{d(1-\rho)}{(1-a)(1-c)}}\right]^{\frac{1}{1-\frac{(1-a \theta)(1-c \rho)}{(1-a)(1-c)}}}$. For the second group it is similar.
} 
$\frac{\partial L_{2}}{\partial K_{2}}>0$ is stronger than the first one, $\frac{\partial L_{1}}{\partial K_{2}}<0$. The intuitive reason for this is that appropriation involves a friction cost, i.e. $\rho<1$. Therefore the increased incentives for production of the formerly capital-poor group 2 are not fully offset by the enhanced appropriation incentives of group 1 . This is displayed in the equation below (for convenience and without loss of generality the parameter values are taken as symmetrical):

$$
\left|\frac{\partial L_{2}}{\partial K_{2}}\right|-\left|\frac{\partial L_{1}}{\partial K_{2}}\right|=(1-\rho)\left(\frac{b}{1-a}\right)\left(\frac{\alpha a}{\beta^{\rho}}\right)^{\frac{1}{1-a}} K_{1}^{\frac{b-d \rho+a-1}{1-a}} L_{2}^{\frac{1-c \rho}{1-a}}>0
$$

Redistribution leads to a more substantial rotation of group 2's reaction function than of group 1's reaction function. In this way the basin of attraction of the good equilibrium should usually increase. Thus, when a part of the capital of the capital-rich group is not fully employed in the production process, but consumed, capital and land redistribution can reduce conflict. Redistribution of capital that is not productively employed could take the form of a tax on certain luxury goods.

Another caveat is that in a setting with intra-group inequality capital redistribution can reduce conflict. This is the case studied in Grossman (1994). Also in the present framework we obtain under some conditions this result when we allow for intra-group inequality. ${ }^{19}$

The findings of this subsection are summarized in the following proposition:

Proposition 3 Capital redistribution is not an efficient measure to reduce conflict, if all capital is employed in production. When a part of the capital is consumed rather than invested, redistribution can lead to less appropriation.

Proof. Follows from equation (11) and the discussion above.

\subsection{Education, Public Health and Poverty Alleviation Pro- grammes}

In this part we will examine what happens if taxation revenue is not simply transferred, but spent on education, health and poverty-alleviation programmes, which eventually lead to a higher total factor productivity. Thus, we have the following payoff function for group 1 (for group 2 it is analogous):

$$
V_{1}=L_{2}(1-t) y_{1}+\left(1-L_{1}\right)\left[(1-t) y_{2}\right]^{\rho}
$$

Introducing the production functions in (12), we obtain:

\footnotetext{
${ }^{19}$ The derivations of the case with intra-group inequality are available from the author.
} 


$$
V_{1}=L_{2}(1-t) \alpha(t) L_{1}^{a} K_{1}^{b}+\left(1-L_{1}\right)(1-t)^{\rho}(\beta(t))^{\rho} L_{2}^{c \rho} K_{2}^{d \rho}
$$

Please note that now $\alpha$ and $\beta$ are assumed to be strictly increasing concave functions of t, i.e. $\alpha=\alpha(t)$ and $\beta=\beta(t)$.

We obtain reaction function (14) for group 1 (it is analogous for group $2)$ :

$$
L_{1}=(\alpha(t))^{\frac{1}{1-a}}(\beta(t))^{\frac{-\rho}{1-a}} a^{\frac{1}{1-a}} K_{1}^{\frac{b}{1-a}} K_{2}^{\frac{-d \rho}{1-a}} L_{2}^{\frac{1-c \rho}{1-a}}(1-t)^{\frac{1-\rho}{1-a}}
$$

The partial derivative of $L_{1}$ with respect to $t$ is positive under the condition that $\frac{1}{\alpha} \frac{\partial \alpha}{\partial t}-\frac{\rho}{\beta} \frac{\partial \beta}{\partial t}>\frac{1-\rho}{1-t}$.

This means that education, health and anti-poverty spending are likely to increase the labour time of a given group if it has a low initial level of total factor productivity and if the policy measures much increase its productivity. By contrast, the increase in the total factor productivity of the opponent tends to decrease the first group's incentives to pursue productive activities. This is intuitive, as an increase in the productivity of the opponent group makes it a more attractive target. However, for most parameter values it is likely that these three policies lead to less conflict overall, as the conflictreducing term $\frac{1}{\alpha} \frac{\partial \alpha}{\partial t}$ is multiplied by 1 , whereas the conflict-enhancing term $\frac{1}{\beta} \frac{\partial \beta}{\partial t}$ is multiplied by $\rho<1$.

This becomes more apparent, if we focus on the symmetrical case, where $\alpha=\beta$. In this case, the condition for education, health and anti-poverty spending to reduce conflict becomes: $\frac{\partial \alpha}{\partial t}>\frac{\alpha(t)}{(1-t)}$.

It follows from our assumptions that taxation has a positive impact on the total factor productivity $\alpha$. Thus, $\frac{\partial \alpha}{\partial t} \geq 0$. The concavity assumption implies that the marginal productivity of taxation spending is strictly decreasing. Thus, $\frac{\partial^{2} \alpha}{(\partial t)^{2}}<0$.

For low levels of $\alpha$ and t the derivative $\frac{\partial \alpha}{\partial t}$ is big, and it is likely that condition $\frac{\partial \alpha}{\partial t}>\frac{\alpha(t)}{(1-t)}$ holds. Proposition 4 summarizes these insights.

Proposition 4 When the total factor productivity is a strictly increasing concave function of education, health and poverty-alleviation spending, marginally increasing the public expenditures for these policies increases the overall time spent on productive activities if the country is "stuck" in a low productivity-and low taxation- equilibrium.

Proof. Follows from equation (14) and the discussion above.

The policy implications for reducing conflict, i.e. to increase spending on education, health and poverty-alleviation programmes if total factor productivity is low, appear reasonable. Increases in education, health and anti-poverty spending benefit above all the "low productivity" group. This is the case because the marginal productivity of these policies is decreasing. 
The "low productivity" group is in general the most likely to choose a high level of appropriative activities. Therefore, education, health promotion and poverty-alleviation programmes are well-focused.

Furthermore, independently of the impact of an increase in the total factor productivity on the labour supply of the two groups, such an increase in the total factor productivity could result in a higher output $y_{i}$. In fact, there is a trade-off between the costs of these kinds of public expenditures and their returns. However, this issue is already well-documented in the literature and is not directly related to our main focus.

\section{Empirical Evidence}

It is important to assess whether our theoretical findings are reasonable in the light of empirical evidence. As discussed below, due to a lack of appropriate data we are not able to perform a direct empirical test of the theory. Therefore we have to limit ourselves to a very general inquiry into the impact of the welfare state on conflict.

In the literature there have been several influential empirical studies of civil wars that use cross-country panels (see Fearon and Laitin, 2003; Collier and Hoeffler, 2004; Miguel, Satyanath and Sergenti, 2004). These studies have mostly focused on socioeconomic explanatory factors of civil conflicts such as economic growth, wealth, ethnicity, natural resources, and population. There has been little empirical evidence about the impact of welfare state policies on the likelihood of civil war outbreaks. I would like to address this shortcoming.

For assuring comparability, I will apply the same data, method and core specification as used in Fearon and Laitin (2003), one of the most influential papers in the field. I will update the data for a further five years (2000-2004) and include welfare state variables. Also, I will include several additional robustness tests not performed in Fearon and Laitin (2003), using alternative methods, independent or dependent variables.

\subsection{The Data and Method}

Panel data for 155 countries from 1965 to 2004 will be used to explain the likelihood of the outbreak of a civil war. All countries that had a population of at least half a million in 1990 were included. The start date of 1965 has been chosen for the reason that, for several of the variables included, there is no data before 1965. All variables are described in Appendix B.

As is done in Fearon and Laitin (2003), and in almost all other papers in the field, I will explain the outbreak of wars rather than the number of periods of fighting. As dependent variable, civil war onset data from Fearon and Laitin (2003) has been used. It has been updated for the years 2000 to 2004 using the "Data on Armed Conflicts" database of PRIO (2006, in 
collaboration with the University of Uppsala). All internal conflicts that cause more than 1000 battle related deaths for the whole conflict are coded as civil wars. This is a dummy variable that takes the value of 1 for an outbreak of war, and 0 if no outbreak of a new war occurs.

The main explanatory and control variables are taken from various sources. The first welfare state variable included corresponds to "general government consumption expenditure" in percent of GDP (World Bank, 2006b). This captures the size of the state in terms of the size of the economy. The data is available for most countries and years between 1965 and 2004 .

It would be more appealing to use a variable such as "social spending" or "extent of redistribution", rather than general government expenditure. However, the data on general government expenditure has the important advantage of being available for most countries and years and allows for minimizing the number of missing observations, while the data on social spending from sources like the government statistics of the IMF is only available for few countries and years.

It seems defendable to include general government spending in percent of GDP as a proxy for redistribution, given that typically the states with most redistribution (for example, the Scandinavian countries) also have the highest overall level of state expenditure. The Pearson correlation between the data on general government spending and the data on social spending that is only available for OECD countries (cf. OECD, 2007) is as high as 0.79 . This could indicate that most of the inter-country variation in general government expenses is due to differences in social transfers, while other forms of government spending, for example for infrastructure, may vary less.

To make sure that the government spending variable does not pick up the effects of military spending, we include military expenditures as a control variable in the regressions. Thus, the coefficient of government spending reflects the impact of all non-military government expenditures, most of which have some redistributive component.

The other welfare state variable used as an explanatory variable in this section is the level of education spending as a percentage of GDP (World Bank, 2006a). Data for this variable is available from 1970 to 2004, although not all years are covered.

As shown later, other potential welfare state indicators such as health spending (World Bank, 2006b), which is only available for certain countries and years between 1990 and 2004, cannot be included in the regression analysis due to a lack of observations.

The control variables are the same as the ones included in Fearon and Laitin (2003), but are updated for the years 2000 to 2004 using the same method as applied by these authors. Also further variables are included in the robustness checks. These variables are from various sources and are explained in detail in Appendix B. 


\begin{tabular}{|lccc|}
\hline & Sample & No civil war & Civil war \\
Goverment spending (in \% of GDP), first lag & 15.484 & 15.523 & 12.82 \\
& $(\mathrm{n}=4597)$ & $(\mathrm{n}=4532)$ & $(\mathrm{n}=65)$ \\
Education spending (in \% of GDP), first lag & 4.349 & 4.36 & 3.358 \\
& $(\mathrm{n}=2462)$ & $(\mathrm{n}=2433)$ & $(\mathrm{n}=29)$ \\
Health spending (in \% of GDP), first lag & 5.905 & 5.914 & 4.26 \\
& $(\mathrm{n}=922)$ & $(\mathrm{n}=917)$ & $(\mathrm{n}=5)$ \\
\hline
\end{tabular}

Table 1: Descriptive statistics

In the empirical study of civil wars several methodological issues arise. Having a limited dependent variable I will, like Fearon and Laitin (2003), Collier and Hoeffler (2004), and the vast majority of papers in the field, perform logit regressions. Other estimators are included in the robustness checks.

An important issue is the direction of causality between outbreaks of civil wars on one hand and economic output and welfare state policies on the other hand. A negative correlation between these variables could be due to welfare spending and economic performance decreasing the risk of civil wars or due to the depressing effect of war on the economy and on public spending. Miguel, Satyanath and Sergenti (2004) have solved this endogeneity problem with the help of instrumental variables (rainfall) for economic shocks. Fearon and Laitin (2003) and Collier and Hoeffler (2004) have addressed endogeneity concerns using lags. For assuring comparability, I will include like Fearon and Laitin (2003) lags in the core specifications. However, I will instrument for government spending and for education as robustness checks.

\subsection{The Results}

Descriptive statistics are useful for gaining an overall view. In table 1 the different means of government, education, and health spending in percent of GDP are displayed for the whole sample included in the data set, as well as split between the country years that experience an outbreak of civil war and the others.

The country years where civil wars broke out are associated with a lower level of government spending (significant at a 1\% level), a lower proportion of education spending (significant at a 1\% level), and less health spending (significant at a $5 \%$ level).

When government spending is included in the analysis, most of the civil wars occurring are in the sample $(\mathrm{n}=65)$. It looks more worrying for education spending, where only 29 civil wars are included in the sample, and 
for health spending, where the number of wars drops to 5. According to what control variables are included, these values slightly decrease due to the missing observations in the control variables.

Given that there are so many missing observations for the health variable, it will not be included in the regression analysis. The education variable will first be included without specific treatment of missing values (i.e. the standard method of listwise deletion is used). Later on, the regressions for the education variable will be re-run with missing observations being imputed using "best subset" regressions.

Regressions are now performed in order to estimate the impact of government spending and education spending on the likelihood of civil war outbreaks.

Table 2 displays the main results and some robustness checks for the government spending variable. In column (1) of table 2 the core regression is shown. As predicted by the theoretical model, lagged government expenditures reduce the likelihood of civil war outbreaks at a level of confidence of $95 \%$. All control variables have the same sign as in Fearon and Laitin's (2003) study, with the exception of the democracy variable (which is insignificant in both studies). Also, besides the variable of previous wars, all variables that they found to be statistically significant are as well significant in the present study. Richer countries experience less conflict (which is consistent with our proposition 1), while in more populated, mountainous, oil-rich, recent and instable states civil wars are more likely.

The marginal effects suggest that government spending has a large impact on the conflict risk. A country year with all average characteristics and with the average level of government spending of $15.5 \%$ of GDP has a risk of $0.64 \%$ of experiencing a civil war. By contrast, when a country year with otherwise identical characteristics has only a government spending level of $5 \%$ the conflict risk more than doubles to $1.35 \%$, while for government spending of $30 \%$ of GDP the risk of civil wars drops to only $0.23 \%$.

From column (2) onwards we control for lagged military expenditures ${ }^{20}$, as well as for the lagged growth rate, which was omitted in Fearon and Laitin (2003). As found in Miguel, Satyanath and Sergenti (2004) and Collier and Hoeffler (2004), growth has a negative sign and is statistically significant. The conflict-reducing impact of government spending remains significant at a $5 \%$ level in column (2).

\footnotetext{
${ }^{20}$ Many observations of military expenditures are missing. To avoid a large drop in the sample size, we impute the missing observations of this variable using "best subset" regressions. All variables of the baseline regression of table 2, column (1) have been included for estimating the missing observations. This technique will be described in more detail further below. All our results are robust to the use of other methods of imputation, such as replacing missing observations with the country mean of military spending.
} 


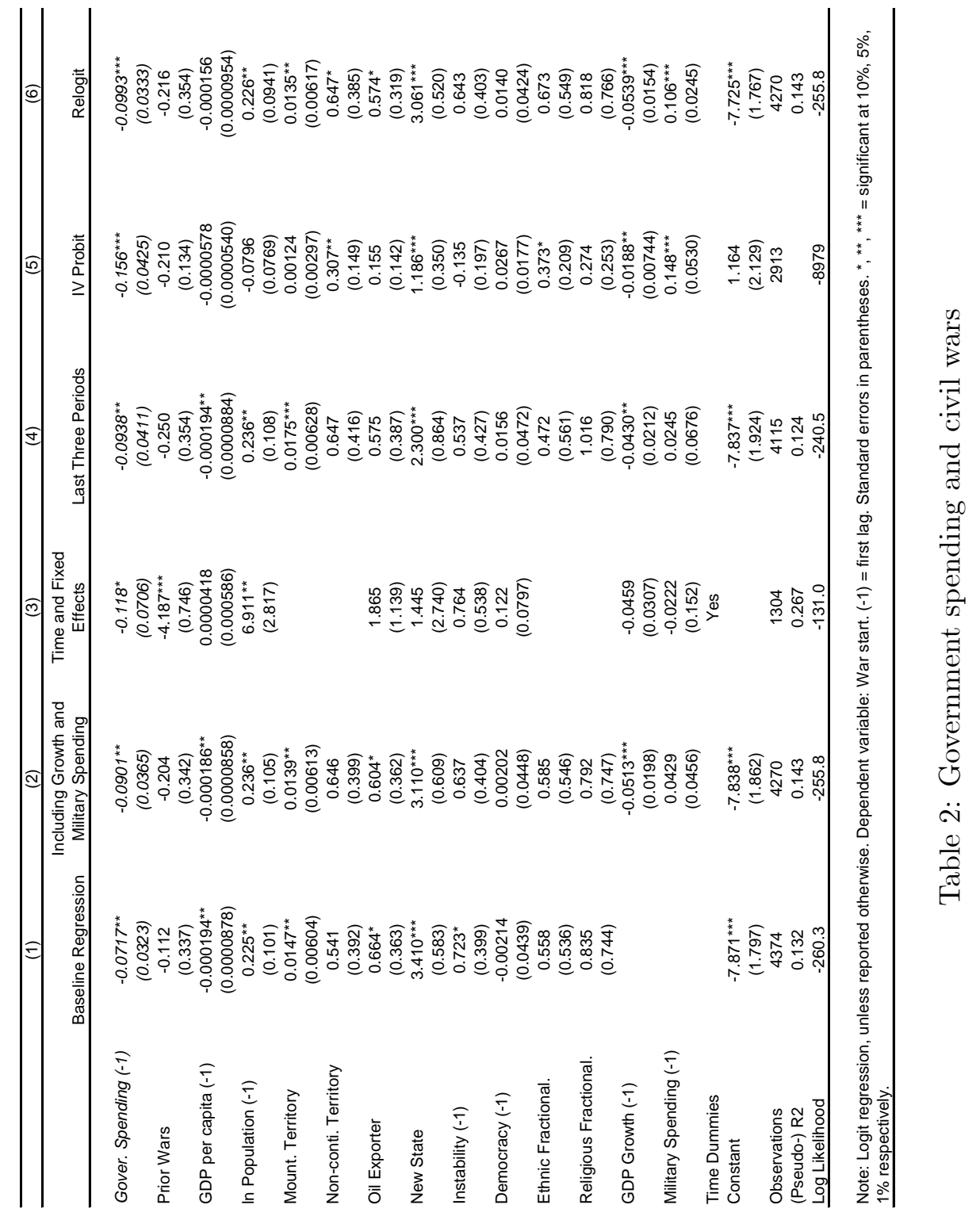


The results of the following columns survive when the growth and/or military spending variables are omitted. I have also tested the model with various other control variables, and the negative effect of government expenditures on conflict always remained statistically significant.

The results are robust to the inclusion of time dummies ${ }^{21}$ and country fixed effects in column (3). The columns (4) and (5) are devoted to endogeneity checks. In column (4) the average of government spending in the last three years is taken as the main explanatory variable. It still remains significant at $5 \%$. In column (5) an IV probit estimation is performed. Two variables that are correlated with government spending are taken as instruments: debt service and the part of the country that is rural. These variables have not been found to be related to the conflict risk in previous studies (cf. Collier, Hoeffler and Rohner, 2009), and the Hansen test suggests that the instruments are valid ( $\mathrm{p}$-value is 0.542 ). Government spending has a war-reducing effect at a confidence level of $99 \%$.

In column (6) the model is reestimated with a rare event logit (Relogit) estimator, using the method of King and Zeng (2001). Again, government spending reduces conflict at a confidence level of $99 \%$.

The next two tables are devoted to studying the impact of education spending in percent of GDP on conflict. As we have seen earlier, there is much more missing data for this variable than for the government spending variable. The number of observations is almost halved.

In column (1) of table 3 the core model with unimputed education spending is displayed. The lagged education variable has the right sign, but is not significant. In column (2) we instrument for education, using the same instruments as in table 2. The instruments pass the Hansen test with a p-value of 0.121 . Now education significantly decreases conflict at a $1 \%$ level.

\footnotetext{
${ }^{21}$ As in some particular years no conflict onsets occur, I have taken 5-year periods for the time dummies.
} 


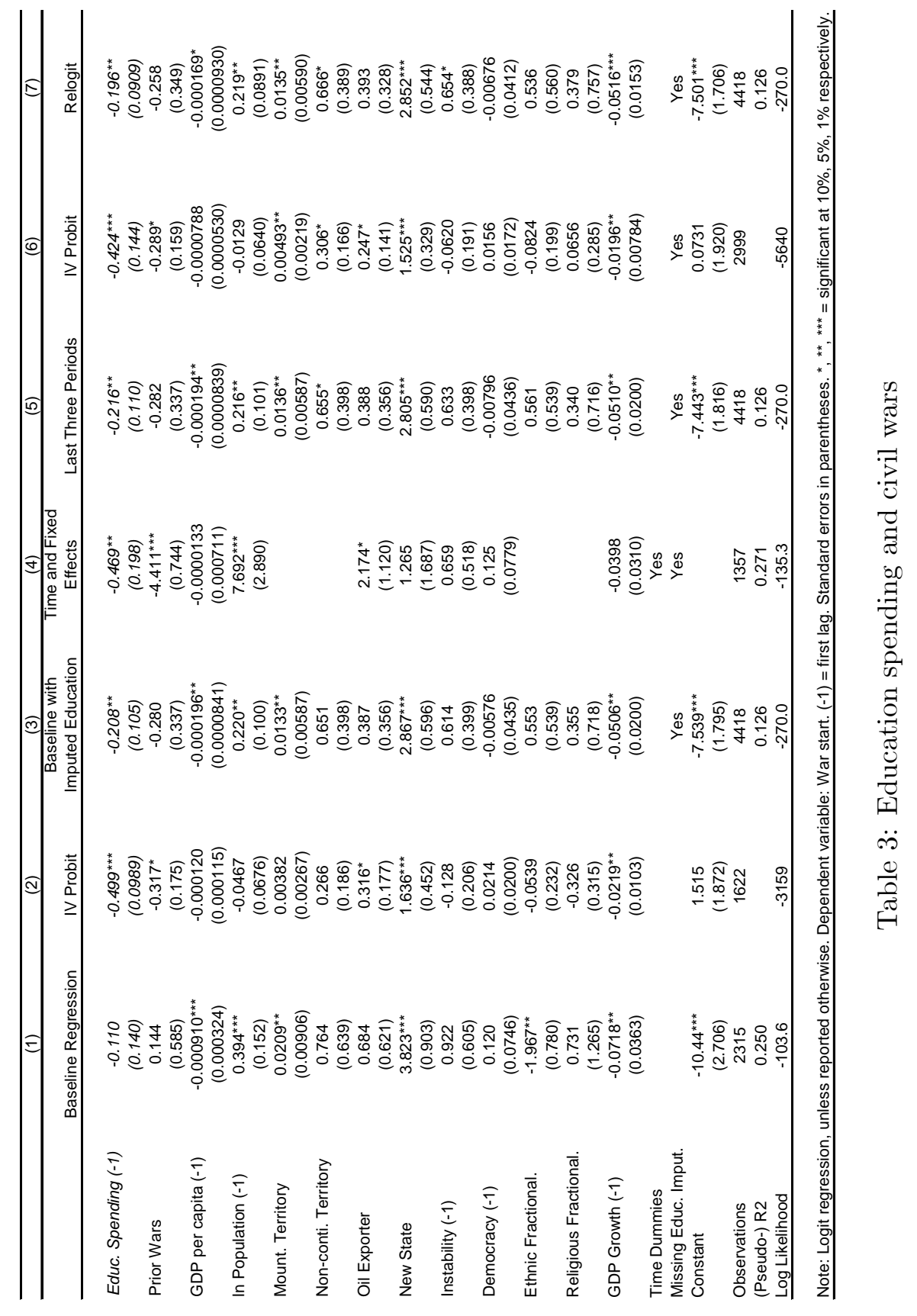


The reason for which the results for education are less clear-cut than for general government spending could be related to the pronounced drop in the sample size and the onsets (for the specification of column (1) only 25 war onsets are included in the sample). There are two ways in which we can investigate this: 1) imputation of the missing observations of the education variable, 2) using alternative dependent variables that have more onsets than the civil wars variable. We shall start with the first possibility.

For countering the problem of data availability, the missing observations of education spending are imputed for the remaining columns of table 3 . The technique of (single) imputation using regression "best subset" estimations has been used ${ }^{22}$. With this technique, missing values are estimated with the help of a regression that includes all other independent variables as well as further variables and accounts for a degree of random error. (Single) regression imputation can be used as long as missing observations are either missing completely at random (MCAR) or missing at random (MAR). This is the case for our data ${ }^{23}$. (Single) regression imputation and multiple imputation have been shown in the literature (Deville and Särndal, 1994; King et al., 2001; Little and Rubin, 2002; Acock, 2005) to be much more effective than other traditional techniques such as mean imputation, conditional mean imputation or missing data indicators. ${ }^{24}$

Column (3) of table 3 is devoted to the core regression with the imputed education data. Education now has a conflict reducing impact that is significant at a $5 \%$ level. This finding is robust to the inclusion of time and country fixed effects in column (4) and to using the average of the last three years of education expenditures as the main explanatory variable in column (5). The IV probit results of column (2) are replicated in column (6) with the imputed education variable, which is significant at a $1 \%$ level (the instruments pass the Hansen test with a p-value of 0.992). Finally, the

\footnotetext{
${ }^{22}$ The imputation was performed in Stata 9 using the "impute" command. The dependent and all independent variables of the core model of table 2, as well as other variables that are correlated with education (the lags 1 to 6 of education, the total life expectancy at birth, the number of hospital beds per 1000 people, the crude birth rate per 1000 people) were included for the estimation of the missing values of the education variable. These three additional variables are all from the World Bank (2006b).

${ }^{23}$ Typically, single and multiple imputation are only problematic when data is not missing at random (NMAR), which is mostly the case for survey and opinion polls data.

${ }^{24}$ From a theoretical point of view, multiple (regression) imputation (which creates a series of different data sets) is even more powerful than single (regression) imputation, as it accounts not only for sampling variation, but as well for imputation variation. In empirical studies both techniques have been found to perform in similarly effective ways (Ezzati-Rice et al., 1993; Acock, 2005). In the present analysis multiple imputation has the disadvantage of being more difficult to apply for the robustness checks, where not only logit estimators are used. However, I have re-run the estimations of the paper using the multiple imputation procedure Amelia (King et al., 2001) and other methods such as mean imputation, conditional mean imputation etc and have found similar results as with single imputation.
} 


\begin{tabular}{|c|c|c|c|c|}
\hline & $(1)$ & (2) & (3) & (4) \\
\hline & Coups & Guerrilla Warfare & Assassinations & General Strikes \\
\hline \multirow[t]{2}{*}{ Educ. Spending (-1) } & $-0.274^{\star *}$ & $-0.0204^{\star \star *}$ & $-0.0486^{\star * *}$ & $-0.0370^{* * *}$ \\
\hline & (0.109) & $(0.00475)$ & (0.0124) & $(0.00725)$ \\
\hline \multirow[t]{2}{*}{ GDP per capita (-1) } & $-0.000228^{*}$ & $-0.00000789^{\star \star \star}$ & $-0.0000160^{\star \star \star}$ & $-0.00000521^{\star \star \star}$ \\
\hline & $(0.000124)$ & $(0.00000122)$ & $(0.00000319)$ & $(0.00000187)$ \\
\hline \multirow[t]{2}{*}{ In Population (-1) } & -0.0917 & $0.0386^{\star \star \star}$ & $0.0449^{\star \star \star}$ & $0.0369^{\star \star \star}$ \\
\hline & $(0.128)$ & $(0.00604)$ & $(0.0157)$ & (0.00922) \\
\hline \multirow{2}{*}{ Mount. Territory } & 0.00774 & $0.00165^{\star \star \star}$ & $0.00472^{* \star *}$ & 0.000527 \\
\hline & $(0.00643)$ & $(0.000394)$ & $(0.00103)$ & $(0.000602)$ \\
\hline \multirow{2}{*}{ Non-conti. Territory } & -0.644 & $0.202^{\star \star \star}$ & $0.262^{\star \star \star}$ & -0.00170 \\
\hline & $(0.776)$ & $(0.0237)$ & $(0.0618)$ & $(0.0362)$ \\
\hline \multirow[t]{2}{*}{ Oil Exporter } & -0.138 & 0.0186 & $0.160^{\star * \star}$ & 0.00946 \\
\hline & $(0.511)$ & $(0.0230)$ & $(0.0599)$ & $(0.0351)$ \\
\hline \multirow[t]{2}{*}{ New State } & 1.247 & -0.0871 & -0.189 & -0.131 \\
\hline & (1.098) & $(0.0836)$ & $(0.218)$ & $(0.128)$ \\
\hline \multirow[t]{2}{*}{ Instability $(-1)$} & 0.561 & $-0.0870^{\star *}$ & -0.0584 & 0.0794 \\
\hline & $(0.470)$ & $(0.0341)$ & $(0.0888)$ & $(0.0521)$ \\
\hline \multirow[t]{2}{*}{ Democracy $(-1)$} & -0.0261 & $0.00896^{\star * *}$ & $0.0292^{\star \star *}$ & $0.0264^{\star \star *}$ \\
\hline & $(0.0523)$ & $(0.00233)$ & $(0.00608)$ & $(0.00357)$ \\
\hline \multirow[t]{2}{*}{ Ethnic Fractional. } & 0.550 & $0.186^{\star \star \star}$ & -0.0395 & 0.0835 \\
\hline & $(0.677)$ & $(0.0341)$ & $(0.0890)$ & $(0.0521)$ \\
\hline \multirow[t]{2}{*}{ Religious Fractional. } & -0.296 & $-0.162^{\star \star \star}$ & $-0.479^{\star * \star}$ & $-0.389^{\star \star \star}$ \\
\hline & $(0.882)$ & $(0.0409)$ & $(0.106)$ & $(0.0624)$ \\
\hline \multirow[t]{2}{*}{ GDP Growth (-1) } & -0.0271 & -0.00173 & $-0.0150^{\star \star *}$ & $-0.00864^{\star \star \star}$ \\
\hline & $(0.0296)$ & $(0.00156)$ & $(0.00405)$ & $(0.00238)$ \\
\hline \multirow[t]{2}{*}{ Constant } & -1.169 & $-0.474^{\star \star \star}$ & -0.263 & -0.247 \\
\hline & (2.210) & $(0.103)$ & $(0.270)$ & $(0.158)$ \\
\hline Observations & 2214 & 2229 & 2229 & 2229 \\
\hline (Pseudo-) R2 & 0.109 & 0.146 & 0.075 & 0.077 \\
\hline Log Likelihood & -178.4 & -974.5 & -3110 & -1919 \\
\hline
\end{tabular}

Note: Column(s) (1) = Logit, (2) to (4) = OLS. Dependent variable: as stated in the second row. $(-1)=$ first lag. Standard errors in parentheses. ${ }^{\star},{ }^{\star \star},{ }^{\star \star \star}=$ significant at $10 \%, 5 \%, 1 \%$ respectively.

Table 4: Education spending and political violence

results also hold for the use of the Relogit estimation method in column (7).

Also quantitatively, the impact of education on the risk of civil war is substantial (the following marginal effects are based on column (3)). A country year with all average characteristics and a level of education spending as percentage of GDP of $6 \%$ has the risk of a civil war outbreak in a particular period of $0.49 \%$, while a country year with otherwise identical characteristics, but with an education spending of $2 \%$, has a conflict risk of $1.04 \%$ which is more than double.

In table 4 we implement the second possibility for dealing with the reduced sample size (and do not apply imputation of missing values): We use other forms of political violence and contention as dependent variables. These variables are taken from Banks (2005) and are described in detail in Appendix B. The four variables used, coups (40 onsets), guerrilla warfare (251 onsets), political assassinations (245 onsets) and general strikes (261 onsets) have significantly more onsets than the civil war variable (25 onsets) after inclusion of education. ${ }^{25}$ For all four dependent variables education

\footnotetext{
${ }^{25}$ Different forms of political violence have different main explanatory factors. However, all these phenomena have in common that they are associated with politically motivated violence, and that they could at least partially be caused by grievances due to deprivation
} 
has a violence-reducing effect (significant at a 5\%, resp. $1 \%$ level).

\section{Conclusion}

The present contribution has studied the impact of deprivation in unequal societies on the choice between appropriative and productive activities, and the question of whether welfare state policies may be able to reduce the equilibrium level of appropriation. Conflict has been represented as mutual stealing, whereas a friction of fighting has been included. Using fully specified production functions has allowed for both symmetrical outcomes, and for the inclusion of inequality in capital endowments and in total factor productivity. It has been shown that population groups with a lower total factor productivity spend more time on appropriation.

In the present model, income taxation reduces the incentives for appropriation above all if the economy is stuck in a low production trap. For higher levels of production, under certain conditions the undesirable impact of distortions and disincentives for productive work due to taxation may prevail. Capital and land redistribution can reduce appropriation if not all capital is employed in production. Education, health and anti-poverty spending have above all an appropriation-reducing impact if the total factor productivity is initially low.

Empirical evidence has been presented that is consistent with the model's predictions. Higher government and education spending lower the risk of civil wars. The results are statistically significant for various specifications and for several robustness checks.

Further research in this area should be encouraged: Generalizing the findings for an n-player framework would be useful. Testing the results of the present contribution more directly with very detailed micro-level data would also be an interesting research venue.

\section{References}

Acock, Alan. (2005). "Working With Missing Values", Journal of Marriage and Family, 67, 1012-28.

Alston, Lee, Gary Libecap and Bernardo Mueller. (2000). "Land Reform Policies, the Sources of Violent Conflict, and Implications for Deforestation in the Brazilian Amazon", Journal of Environmental Economics and Management, 39, 162-88.

and low levels of redistribution. For guaranteeing the comparability of the results, the control variables of Fearon and Laitin (2003) will be included as before. These control variables are likely to capture most of the relevant explanatory factors, although obviously the explanatory power of each individual variable is expected to vary according to which dependent variable is used. 
André, Catherine and Jean-Philippe Platteau. (1998). "Land relations under unbearable stress: Rwanda caught in the Malthusian trap", Journal of Economic Behavior and Organization, 34, 1-47.

Azam, Jean-Paul. (2001). "The Redistributive State and Conflicts in Africa", Journal of Peace Research, 38, 429-44.

Bandiera, Oriana. (2003). "Land Reform, the Market for Protection, and the Origins of the Sicilian Mafia: Theory and Evidence", Journal of Law, Economics, and Organization, 19, 218-44.

Banks, Arthur. (2005). "Cross-National Time-Series Data Archive", Binghamton NY, Databanks International, data file.

Berrebi, Claude. (2007). "Evidence About the Link Between Education, Poverty and Terrorism Among Palestinians", Peace Economics, Peace Science and Public Policy, 13, Issue 1, Article 2.

Besley, Timothy and Torsten Persson. (2009). "Repression and Civil War?", forthcoming American Economic Review.

Besley, Timothy and Torsten Persson. (2009b). "The Incidence of Civil War: Theory and Evidence", mimeo, London School of Economics and Stockholm University.

Brito, Dagobert and Michael Intriligator. (1985). "Conflict, War, and Redistribution", American Political Science Review, 79, 943-57.

CIDCM (Center for International Development and Conflict Management). (2007). "Polity IV project", University of Maryland, data file.

Collier, Paul and Anke Hoeffler. (2004). "Greed and grievance in civil war", Oxford Economic Papers, 56, 563-95.

Collier, Paul, Anke Hoeffler, and Dominic Rohner. (2009). "Beyond Greed and Grievance: Feasibility and Civil War", Oxford Economic Papers, 61, $1-27$.

Collier, Paul and Dominic Rohner. (2008). "Democracy, Development, and Conflict", Journal of the European Economic Association, 6, 531-40.

Dal Bo, Ernesto and Pedro Dal Bo. (2008). "Workers, Warriors and Criminals: Social Conflict in General Equilibrium", mimeo, Stanford University and Brown University.

Deininger, Klaus. (2003). "Causes and Consequences of Civil Strife: Microlevel Evidence from Uganda", Oxford Economic Papers, 55, 579-606. 
Deville, Jean-Claude and Carl-Erik Särndal. (1994). "Variance Estimation for the Regression Imputed Horvitz-Thompson Estimator", Journal of Official Statistics, 10, 381-94.

Do, Quy-Toan and Lakshmi Iyer. (2007). "Poverty, Social Divisions, and Conflict in Nepal", mimeo, World Bank and Harvard Business School.

Ezzati-Rice, Trena, Meena Khare, Donald Rubin, Roderick Little and Joseph Schafer. (1993). "A Comparison of Imputation Techniques in the Third National Health and Nutrition Examination Survey", American Statistical Association Proceedings of the Survey Research Questions Section, 303-8.

Fearon, James and David Laitin. (2003). "Ethnicity, Insurgency, and Civil War", American Political Science Review, 97, 75-90.

Gentzkow, Matthew and Jesse Shapiro. (2004). "Media, Education and AntiAmericanism in the Muslim World", Journal of Economic Perspectives, 18, $117-33$.

Grossman, Herschel. (1994). "Production, Appropriation, and Land Reform", American Economic Review, 84, 705-12.

Grossman, Herschel. (1995). "Robin Hood and the Redistribution of Property Income", European Journal of Political Economy, 11, 399-410.

Grossman, Herschel and Minseong Kim. (1995). "Swords or Plowshares? A Theory of the Security of Claims to Property", Journal of Political Economy 103: $1275-88$.

Grossman, Herschel and Minseong Kim. (2003). "Educational Policy: Egalitarian or Elitist?", Economics and Politics, 15, 225-46.

Justino, Patricia. (2005). "Redistribution, Inequality and Political Conflict", PRUS working paper 18, University of Sussex.

King, Gary, James Honaker, Anne Joseph and Kenneth Scheve. (2001). "Analyzing Incomplete Political Science Data: An Alternative Algorithm for Multiple Imputation", American Political Science Review, 95, 49-69.

King, Gary and Langche Zeng. (2001). "Logistic Regression in Rare Events Data", Political Analysis, 9, 137-63.

Krueger, Alan and Jitka Maleckova. (2003). "Education, Poverty and Terrorism: Is There a Causal Connection?", Journal of Economic Perspectives, $17,119-44$. 
Little, Roderick and Donald Rubin. (2002). Statistical Analysis with Missing Data, Hoboken NJ, Wiley-Interscience, Wiley Series in Probability and Statistics.

Miguel, Edward, Shanker Satyanath and Ernest Sergenti. (2004). "Economic Shocks and Civil Conflict: An Instrumental Variables Approach", Journal of Political Economy, 112, 725-53.

Muller, Edward and Mitchell Seligson. (1987). "Inequality and Insurgency", American Political Science Review, 81, 425-52.

Noh, Suk Jae. (2002). "Production, Appropriation, and Income Transfers", Economic Inquiry, 40, 279-87.

OECD (Organisation for Economic Co-operation and Development). (2007). Social Expenditure Database, Paris, OECD, data file.

PRIO (International Peace Research Institute, Oslo). (2006). Data on Armed Conflicts, Oslo, PRIO, data file.

Rohner, Dominic. (2006). "Beach Holiday in Bali or East-Timor? Why Conflict Can Lead to Under- and Overexploitation of Natural Resources", Economics Letters, 92, 113-7.

Rohner, Dominic, and Bruno S. Frey. (2007). "Blood and Ink! The CommonInterest-Game Between Terrorists and the Media", Public Choice, 133, 12945 .

Sweig, Julia. (2002). "What Kind of War for Colombia?", Foreign Affairs, $81,122-41$.

World Bank. (2006a). EdStats (Education statistics database), Washington DC, World Bank, data file.

World Bank. (2006b). World Development Indicators, Washington DC, World Bank, data file.

\section{Appendix A - Functional Forms for Modelling Ap- propriation}

As mentioned earlier, including both ratio-form or difference-form contest success functions and Cobb-Douglas production functions leads to a model that is not analytically solvable. Thus, below I shall first shortly discuss the results for a framework with ratio-form contest success functions and simplified production functions. The same setting is used as above in equation (2), but now in the production functions $L_{1}$ is included instead of $L_{1}^{a}$, and $L_{2}$ instead of $L_{2}^{c}$. 


$$
V_{1}=\frac{\left(1-L_{1}\right)}{\left(1-L_{1}\right)+\left(1-L_{2}\right)}\left(\alpha L_{1} K_{1}^{b}+\beta^{\rho} L_{2}^{\rho} K_{2}^{d \rho}\right)
$$

This leads to the following reaction function for $L_{1}$ (it is analogous for $\left.L_{2}\right)$.

$$
L_{1}=2-L_{2}-\sqrt{\left(1-L_{2}\right)\left(2-L_{2}+\frac{\beta^{\rho} K_{2}^{d \rho} L_{2}^{\rho}}{\alpha K_{1}^{b}}\right)}
$$

These reaction functions are now hump-shaped and there exists a unique stable interior Nash equilibrium. As in the basic model, we have $\frac{\partial L_{1}}{\partial K_{1}}>0$, $\frac{\partial L_{1}}{\partial \alpha}>0, \frac{\partial L_{1}}{\partial K_{2}}<0, \frac{\partial L_{1}}{\partial \beta}<0$. Importantly the implications with respect to Welfare state policies would be the same for this functional form as in section 3. In particular, the effect of income taxation is non-linear, but it decreases appropriation in most cases, especially when $\rho$ is high and initial production efforts are low. Further, capital redistribution is not an efficient measure for reducing conflict, while education and related policies are most suited to reduce appropriation when initial level of total factor productivity are low.

Note that these same policy predictions would also be obtained for difference-form contest success functions with a simplified production function, such as $V_{1}=\left(\frac{1}{2}+\psi\left(\left(1-L_{1}\right)-\left(1-L_{2}\right)\right)\right)\left(\alpha L_{1} K_{1}^{b}+\beta^{\rho} L_{2}^{\rho} K_{2}^{d \rho}\right)$.

\section{Appendix B - Data}

A description and sources of the data used are listed below.

Assassinations: Number of politically motivated murders or attempted murders of high government officials or politicians, from Banks (2005).

Civil war: This variable captures civil conflicts with at least 1000 fatalities per conflict. The data up to 1999 is from Fearon and Laitin (2003), and is updated for the years 2000-2004 using the same definition of civil wars and data from the database on "Armed Conflicts" of PRIO (2006).

Coups: Dummy variable taking a value of 1 if a coup occurred in a given country year, recoded from Banks (2005).

Debt service: Total debt service (\% of GNI), from World Bank (2006b).

Democracy: Polity IV scores, from CIDCM (2007).

Education spending: Public spending on education as percentage of GDP, from World Bank (2006a).

Ethnic fractionalization: Index of ethnic fractionalization, updated variable from Fearon and Laitin (2003).

GDP per capita: Per capita gross domestic product in current US\$, from World Bank (2006b). 
GDP growth: Percentage change on previous year's level of GDP per capita (as defined above).

Government spending: Includes general government final consumption spending in percent of GDP, from World Bank (2006b).

Guerrilla: Number of any armed activity, sabotage, or bombing carried out by independent bands of citizens or irregular forces and aimed at the overthrow of the present regime, from Banks (2005).

Health spending: Public health expenditures as percentage of GDP, provided by the World Bank (2006b).

Instability: Dummy variable taking a value of 1 when there was instability in governing arrangements in any of the previous three years, following Fearon and Laitin (2003)'s definition and using Polity IV scores, from CIDCM (2007).

Military spending: Military expenditures as percentage of GDP, provided by the World Bank (2006b).

Mountainous Territory: Percentage of the territory that is mountainous, updated variable from Fearon and Laitin (2003).

New State: Dummy variable taking a value of 1 when a state was founded in the previous two years, updated from Fearon and Laitin (2003).

Non-contiguous states: Dummy variable taking a value of 1 when a state is not contiguous, updated variable from Fearon and Laitin (2003).

Oil exporter: Dummy variable taking a value of 1 when a country year had greater than $33 \%$ fuel exports, updated variable from Fearon and Laitin (2003).

Population: From World Bank (2006b).

Prior wars: Dummy variable taking a value of 1 when a previous war occurred in a given country.

Religious fractionalization: Index of religious fractionalization, updated variable from Fearon and Laitin (2003).

Rural population: Percentage of population living in rural areas, from World Bank (2006b).

Strikes: Number of general strikes of 1000 or more industrial or service workers that involve more than one employer and that are aimed at national government policies or authority, from Banks (2005). 